\title{
Enabling Curriculum Re-design Through Asynchronous Learning Networks
}

\author{
Alan Staley, Head of Research \\ Niall MacKenzie, Research Fellow \\ Learning Methods Unit \\ University of Central England \\ Perry Barr, Birmingham, B42 2SU \\ England \\ Telephone: +44 (0) 1213316784 \\ Fax: +44 (0) 1213316389 \\ E-mail: alan.staley@uce.ac.uk \\ niall.mackenzie@uce.ac.uk
}

\begin{abstract}
This paper considers existing processes in Higher Education and the opportunity for using Asynchronous Learning Networks (ALNs) to re-design the curriculum. A curriculum model based upon experiential learning, that explicitly links theory and practice, is promoted as the basis for considering the application of technology. The Computer Supported Experiential Learning project at the University of Central England is explained, and appropriate technologies considered at each stage of the learning cycle. Fundamental to this paper is the view that technology should be used to add value to the learning process, and not to simply automate existing processes. The opportunities for experiential learning to take place are considered a priority in the curriculum design process, and the starting point in deciding upon the use of technology.
\end{abstract}

\section{KEYWORDS \\ Constructivism, Reengineering, Experiential Learning, Problem Based Learning}

\section{INTRODUCTION}

The main theme of this paper is to campaign for the use of learning technologies to be used innovatively so that the curricula in Higher Education can be re-designed, unleashing new opportunities for quality learning. Unfortunately, many examples to date indicate a more common approach is to simply automate existing curricula and re-inforce learning processes that have existed for centuries. English and Yazdani [1 (pp. 2)], for example, suggest that, "Many universities are recycling existing teaching materials by putting them on the Web and claiming to be delivering learning through a virtual university"

There seems to be a parallel between what is currently happening in higher education and what has already happened with information technology in the world of business. Hammer [2] commented that investments in information technology delivered disappointing results largely because companies tend to use technology to mechanise old ways of doing business, and embed the technology into outdated and often unsound processes. This paper examines some of the traditional education processes, and considers current applications of learning technology, before promoting a particular curriculum model and describing how technology can be used innovatively to "add value" to the learning process. 
It can be argued that information transfer continues to be the predominant model in higher education, which sees the lecturer transferring an established and accepted body of information to students [3]. In this approach the lecturer controls the learning processes by structuring and sequencing the transfer of information. Teaching methods, therefore, tend to be didactic, and often lecturing remains the dominant method. The effectiveness of lectures has often been questioned [4], [5], and while lectures may achieve certain outcomes, we would suggest that approaches which encourage students to passively absorb information will not produce graduates with the appropriate skills for the information age. In particular, Harvey and Green [6] have established that the skills of being able to learn and adapt to a changing world, together with communication skills, are frequently more in demand by employers than specialist subject knowledge. So why automate this approach?

Automation is happening, and as Crook [7] has identified, the dissemination of hypertext lecture notes is an increasingly common practice. As technology is advancing, this automation is becoming more sophisticated, so that the "voice-lecture" presentation [ 8 ], in its simplest form as PowerPoint slides synchronised with an audio recording of the lecture, is gaining popularity. With increasing bandwidth, the "Holy Grail" appears to be the streaming of video lectures over the Internet. While such webcast courses may have a role to play in pure distance learning, the authors suggest that there is little added value in these developments for mainstream higher education apart from increasing access and flexibility. Indeed, much would appear to be lost. Attending face to face (FTF) lectures can often provide the extrinsic motivation for studying, as well as the much-needed "social glue." The authors question what is driving these developments, and point to financial pressures and scarcity of physical resources [9], consumerisation of education [10], [11], and the seductive nature of technology, rather than pedagogy.

In stark contrast to these developments in synchronous broadcasts, that automate the transmission of information from lecturer to student, considerable potential for new approaches to education may arise through the use of Asynchronous Learning Networks (ALNs). ALNs are defined as follows:

Asynchronous Learning Networks (ALN) are people networks for anytime-anywhere learning. ALN combines self-study with substantial, rapid, asynchronous interactivity with others. In ALN learners use computer and communications technologies to work with remote learning resources, including coaches and other learners, but without the requirement to be online at the same time. The most common ALN communication tool is the World Wide Web [12].

Computer Mediated Communication (CMC) tools, such as e-mail, mailing lists, and conferencing underpin ALNs. In particular, the online conference enables students to interact with others and learn collaboratively. Students post messages to the conference for the entire group to see, unlike the private e-mail communication between student and tutor. Such tools offer considerable potential for re-designing the curriculum and enabling the transition to a more constuctivist approach. Constuctivism [13], [14] promotes the view that learning is an active process in which learners construct meaning, going beyond the information given and discovering principles for themselves. It recognises that knowledge and social context are closely linked and that students should engage in active dialogue with each other, reflecting upon experiences and co-operating in the investigation of problems and worthwhile issues. The role of the tutor is to create the learning environment that promotes active learning and to facilitate the learning process. 
These communication tools can supplement FTF dialogue to good effect and add considerable value to the students learning. In particular the "faceless" nature of the medium has been found to promote a more democratic approach to group discussions [15], [16], allowing less dominant students to contribute, and sensitive issues to be discussed without the immediacy of peer pressure in the classroom. The asynchronous nature of these tools also brings the advantage of being able to reflect upon a comment, pause, possibly investigate the issue further, and then write a considered reply. This is lost in the "rapid fire" of FTF communication and the other synchronous tools.

Such advantages need to be offset by the fact that the text based medium lacks the physical and social cues that are inherent in FTF communication - eye contact, gestures, body language and tone of voice [17]. This, coupled to the permanent nature of contributions, hence the fear of exposing one's ignorance, often leads to a lack of contributions from some students. The "lurking" phenomenon (reading messages but not replying or posting new ones) leading to low levels of activity is well documented [18]. However, the authors' experience suggests that while problems may stem from the limitations of the medium, the major concern is how the medium is used. While ALNs can function in a variety of ways, a common approach is to rely heavily upon the online seminar. Again, are we seeing an automation of an unsound process? The traditional seminar has been defined by Gibbs [19] as a "monologue by a reluctant student to a small reluctant audience on a topic of interest to neither." In practice, the presenter of the seminar paper does most of the learning by way of preparation, then the discussion is dominated by a small number of students whilst the majority say nothing. In the online seminar, where the students read assigned material, prepare summaries of the main issues, and then lead discussions, the outcome can be the same. A series of monologues can result instead of real dialogue.

The online lecture and seminar discussed so far, may assist learners to conceptualise particular topics, but do little to encourage students to apply these theories to "real world" situations or to reflect upon experience. In essence, the technology is being used to reinforce the view that theories are taught at university and "real" learning happens in the workplace. The authors propose that instead of replicating traditional approaches, the technology can be used to explicitly link theory and practice, and therefore bridge the academia/workplace divide. Adopting a constructivist approach to education, we believe that the technology can be used to enable experiential learning online.

\section{THEORY AND PRACTICE}

The Kolb Learning Cycle [20] is a well established curriculum model that explicitly links theory and practice, and is relevant to a wide range of educational contexts from continuing professional development to vocationally oriented undergraduate courses. The model recognises that it is insufficient to simply learn new concepts (abstract conceptualisation), just as it is insufficient to have an experience (concrete experience). The learner must make the link between theory and practice by planning how theories will be put into action (active experimentation), carry out that action, and then reflect upon it, relating what happens back to theory (reflective observation). Students learn experientially by systematically performing learning activities at each stage in sequence.

The authors' view is that courses in traditional higher education often focus primarily on abstract conceptualisation with little opportunity for planning, experience or reflection. Figure 1 suggests that effective experiential learning will take place when all three of the following are prevalent; 
knowledge and skills, a willingness on behalf of the student to apply theory to practice, and most importantly the opportunity for this to happen.

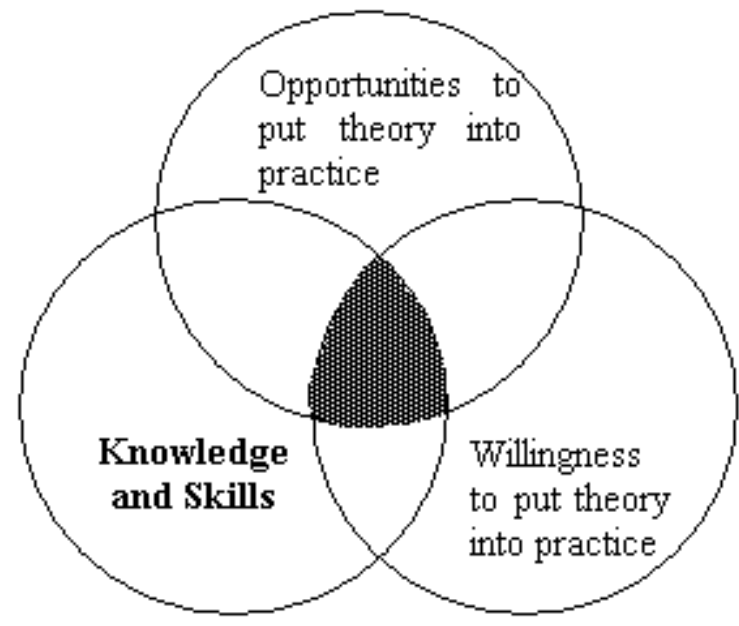

Effective Experiential Learning

(An Adaptation of Honey and Mumford's Learning Opportunities [21])

Figure 1. Conditions for Effective Experiential Learning.

Rather than the starting point for curriculum design being the questions, "what subject content do the students need to know?" and "how many lectures and seminars do they need?" we suggest that a more appropriate question would be, "what opportunities can we create for students to put theory into practice?" Answering this question, thereby addressing the experience stage of the cycle first, might be the key to establishing appropriate uses of technology. In terms of addressing the students' willingness to apply theory to practice, tutors need to consider how intrinsically motivating these experiences might be, and also how favourable are the extrinsic factors, in particular, is this learning assessed in such a way that the students perceive that it is worthwhile? High commitment results only when intrinsic motivation is high and the extrinsic motivation factors are favourable [22].

\section{COMPUTER SUPPORTED EXPERIENTIAL LEARNING}

The Computer Supported Experiential Learning (CSEL) project at the University of Central England in Birmingham, United Kingdom [23], considers the appropriate use of technology at each stage of the learning cycle. Although learning can start at any point in the cycle, this discussion will start with experience, as the use of technology to enhance the opportunity for experience to occur is fundamental to the project. If experiences are to have value then they need to be planned for and reflected upon. The planning and reflection stages are therefore considered next, before conceptualisation--the more typical starting point for curriculum design. The diagrams to illustrate each stage of the cycle are from Gibbs [24]. 


\section{A. Experience}

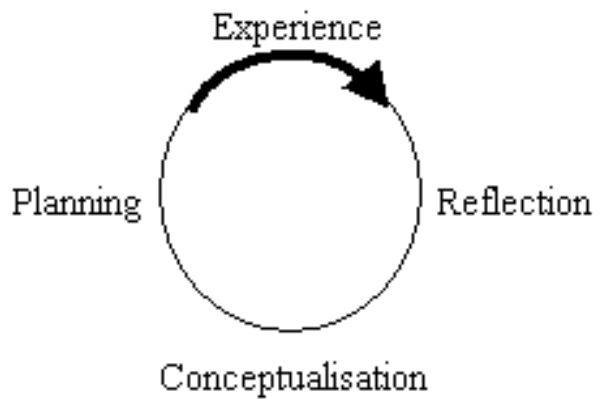

Figure 2. The Experiencing Stage of the Learning Cycle.

Opportunities to put theory into practice will vary enormously depending upon the type of course, level, and in particular, the mode of delivery. The curriculum designer responsible for a part time post-graduate course in professional development will be working in very different context to the curriculum designer responsible for a full-time, Semester One course in a non-vocational subject. However, this opportunity needs to be created, and technology may play a part in enabling this.

\section{Real World Experiences}

In the age of lifelong learning, it is recognised that there is considerable value in work-based learning. It is at work where theories can be tested and concepts applied to real situations. Given that students may be working in different contexts, conflicts may arise between theory and practice that provide the basis for reflection and sharing of experiences in the next stage of the cycle. Part-time courses and student placements provide an ideal opportunity for such experiences, but it must be remembered that the learning comes from connecting theory and practice--they are not separate. The authors recommend that if this opportunity exists, then technology will add little value to this stage of the cycle. Instead, great benefit can be gained by using asynchronous tools elsewhere in the cycle to plan for this experience, and then to reflect upon it.

\section{Artificial Experiences}

Not all courses lend themselves to work-based learning, and even if they do, there will inevitably be situations in which opportunities for putting theory into practice will be limited. As an example, many courses in Business will have modules in Strategic Management, but the opportunity for many students to apply this will not come until much later in their careers, if at all. In these situations it is suggested that academic staff create "substitute experiences" that occur FTF with students. Examples would include role-plays, mock courts and client briefings. In essence, academic staff time is being re-deployed--less time spent involved in information transfer, and more time designing learning activities.

\section{Virtual Experiences}

Where FTF meetings are not possible as in the case of pure distance learning, or where real experiences might be too high risk, expensive, or simply not practical, then the value of technology in creating virtual experiences can be significant. Without the technology there would be no representation of an experience at all - learning would take place in the abstract. Highly 
sophisticated experiences can be created through computer simulations and games. There is also considerable potential for bringing case studies "to life" by incorporating multimedia components, particularly short video clips, to create shareable representations of real world practices that, again, provide the basis for reflection and discussion [25]. Wherever possible, a situated model of learning [26] is recommended--knowledge and skills should be acquired in contexts that reflect the ways in which knowledge will be useful in a real life situation. For an account of how this model has been applied to the design of an interactive multimedia program on medication administration for nurses, see Stillman, Alison, Croker and Tonkin [27]. Original virtual learning environments can be found at Clyde Virtual University [28].

As part of the CSEL project, an online spoof university called "Crumpton" [29] has been established to illustrate a problem-based approach to professional development for academic staff. Problems faced by the university are situated in real world contexts using video clips to provide shareable representations of practice. Examples include a conflict between external examiners, a mutiny in the staff common room, an employer enquiring about the students' skills, inappropriate teaching methods and a student rebellion. The intention of this problem-based curriculum is to provide the motivational context in a humorous way. Once academic staff have analysed the problems there is a structured study programme to follow, and then a conference in which to collaboratively discuss the issues and suggest tentative solutions.

\section{B. Planning for Experience}

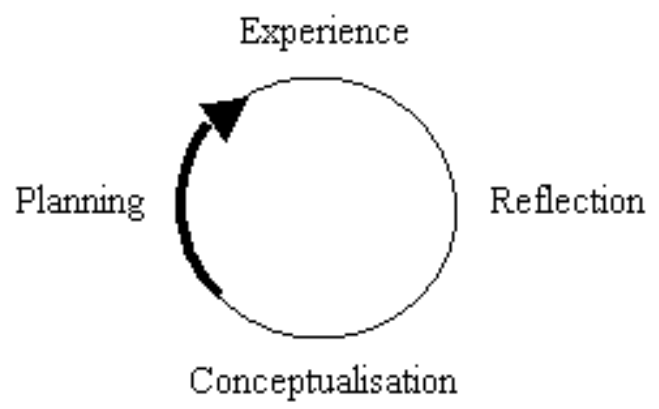

Figure 3. The Planning Stage of the Learning Cycle.

All too often students fail to see the relevance of theoretical concepts in the work place or in applied situations, and do not make connections between theory and practice. The planning stage is important in making these connections explicit. At a simple level, students can e-mail their online tutor or mentor with specific plans of how they intend to apply theory to practice or solve a particular problem.

The CSEL project is also investigating the use of electronic learning contracts (based upon a simple web form) that can enable individual students to personalise their objectives, identify appropriate learning strategies, and consider the evidence that they will need to provide to demonstrate that learning outcomes have been achieved. This seems a way forward in recognising and giving credit for valuable learning that takes place in the workplace, or at least outside of the campus. The approach is also one that fosters learner autonomy by getting students to take responsibility for their own learning. An example of an electronic learning contract is shown in Figure 4 [30]. 


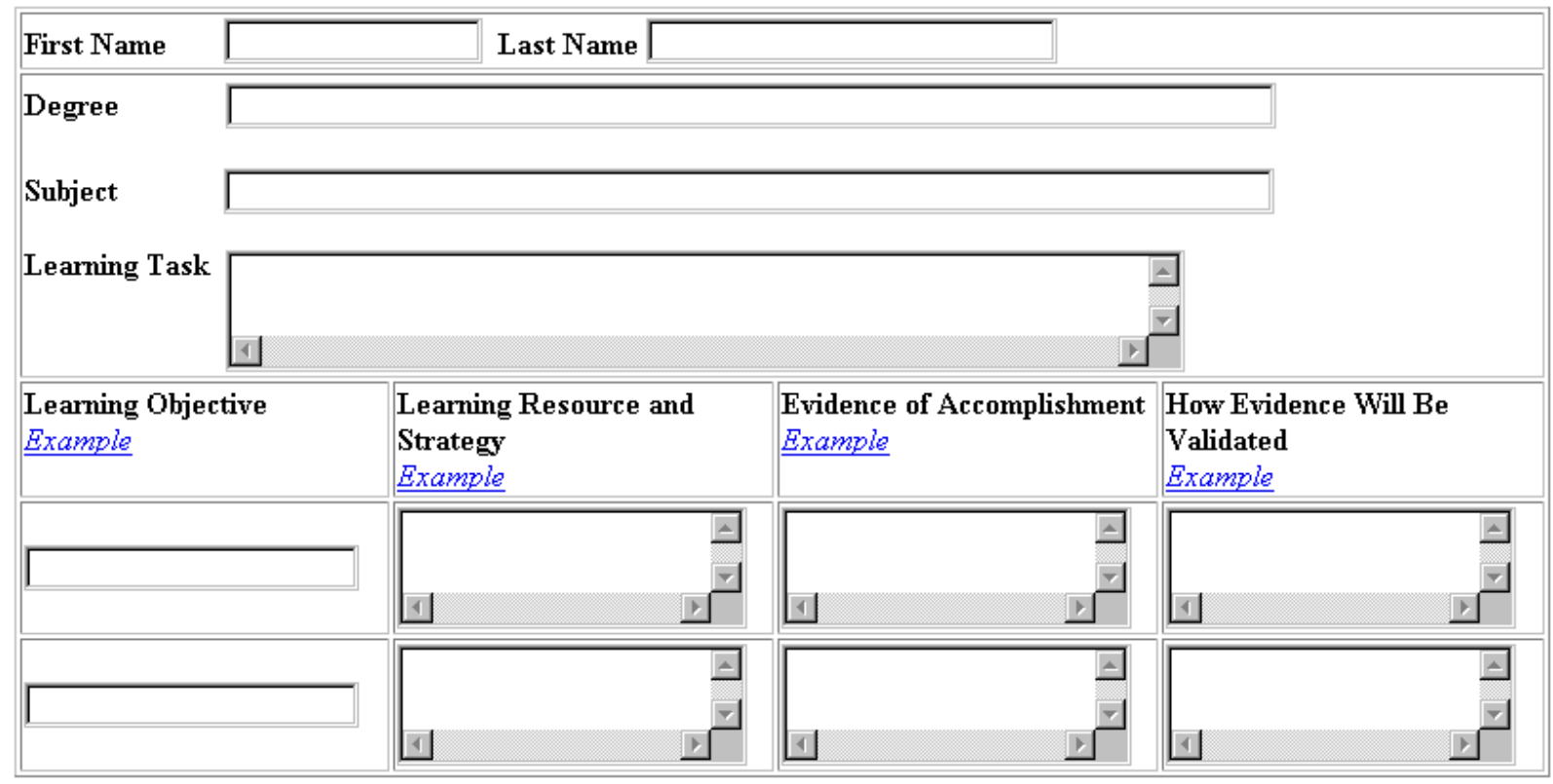

\begin{tabular}{l|l|l} 
Submit & Reset \\
\hline
\end{tabular}

Figure 4. An Example of an Electronic Learning Contract.

Autonomous learning is a highly acclaimed goal for higher education, but one that requires a high level of motivation on behalf of the students, together with good time management skills. The electronic contract will eventually allow learning tasks to be broken down into a series of smaller activities, each of which can be sequenced and estimated in terms of time. This will allow the application of project management techniques such as Gantt charts and Critical Path Analysis to the students' learning.

\section{Reflecting upon Experience}

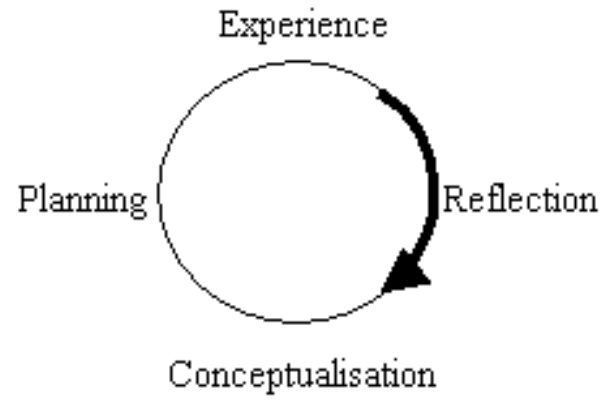

Figure 5. The Reflecting Stage of the Learning Cycle.

At this stage of the learning cycle ALNs using dedicated groupware packages or web-based systems can be very beneficial. The success of ALNs in promoting dialogue and collaborative learning has led to whole courses being delivered this way, with subject content (readings) being 
attached to messages for the student group to discuss. The benefits of this medium have already been noted. However, the authors' experience of such courses has identified two potential problems. Firstly, the readings (often simple text files) may not be particularly stimulating (compared to a multimedia web page), and secondly discussion is often primarily concerned with the concepts in the reading, that is, conceptualisation. Many attempts to use conferencing suffer because of lack of contributions from the student group, although good practice that can sustain active dialogue is emerging [31].

In the CSEL project, conferencing is being promoted as a tool to encourage reflection - not to deliver subject content. According to the Kolb Cycle reflection follows experience. The intention, therefore, is for learners to reflect upon their experiences and relate theory to practice. It is envisaged that students putting theory into practice in the workplace, laboratory or studio, often in isolation from one another, will share experiences, reflect upon what has happened, and support each other through dialogue. The authors expect contributions in this sort of conference to be both more substantial and meaningful than the more typical "online seminar."

\section{Conceptualising}

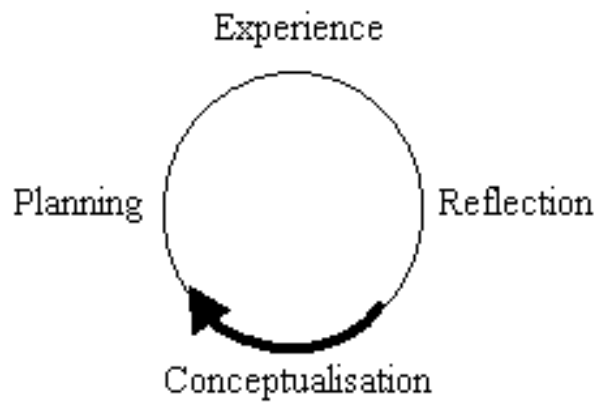

Figure 6. The Conceptualising Stage of the Learning Cycle.

Having designed opportunities for students to put theory into practice, the curriculum designer needs to consider how students will develop the knowledge base and conceptualise theories and ideas that are necessary for the experience to be meaningful. In true constructivist ideology, a problem-based curriculum [32] would encourage small groups of students to actively seek appropriate and relevant knowledge to solve the problem. Increasing student autonomy, and developing "learning to learn" skills is very laudable, although some of the less motivated students and certainly many of the instrumental students will require considerable help and support. In a traditional higher education environment it is the lectures that indicate the subject content that the students should consider. The problem of course is that students often receive this information passively, and then develop a surface approach to learning, relying upon simple recall of factual information, and failing to connect and structure the knowledge base [33], [34].

In applying technology here, the authors recognise that many students will need guidance to the subject content that needs to be considered, but do not recommend providing all of the information for students via the Web. The basic premise of the constructivist approach is that students should "go beyond the information given," and therefore the approach being suggested at this stage of the cycle is to use the Web to provide overviews of subject content and pointers to investigate further. The CSEL project is investigating various representations of this information, in particular mind maps [35] which may appeal to a range of cognitive styles [36], [37]. An example of a web-based mind map is shown in Figure 7. 


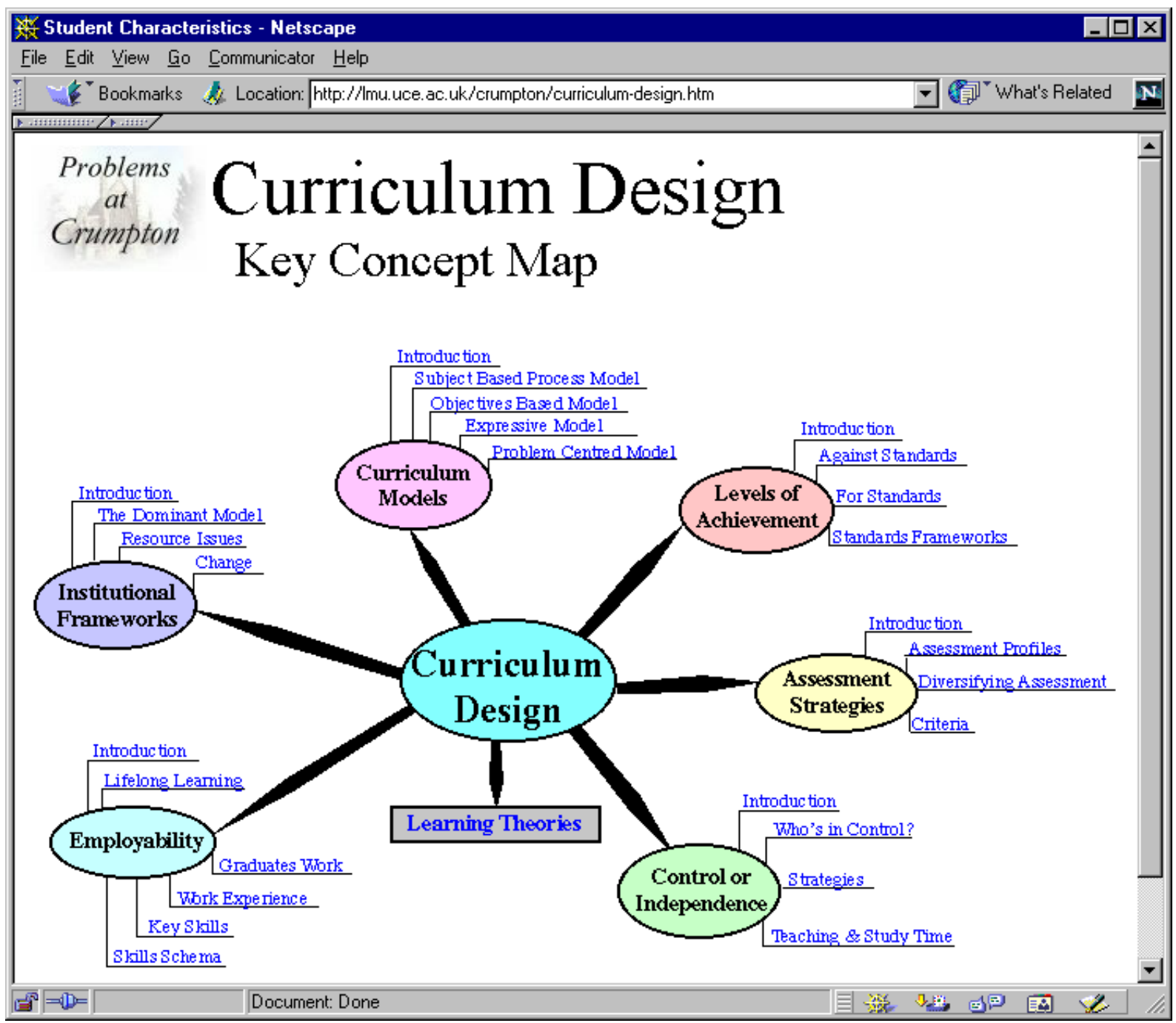

Figure 7. An Example of a Mind Map in Web Format.

If the Web format does not offer any additional value to the learning process than would be provided by other print-based media, then there seems little point in converting these resources for the Web.

Of course, conceptualisation involves much more than passive absorption of information. To engender learner activity and to encourage students to take a deep approach [33] to their learning, it is important that the web pages contain learning activities. Some of these activities may take place at the computer screen, for example, multimedia simulations and objective testing which can be used to check understanding, provide valuable feedback and a sense of achievement. An example of a web-based learning activity that can form the basis of further discussion (FTF or online) is shown in Figure 8. An example of online objective testing is shown in Figure 9. 


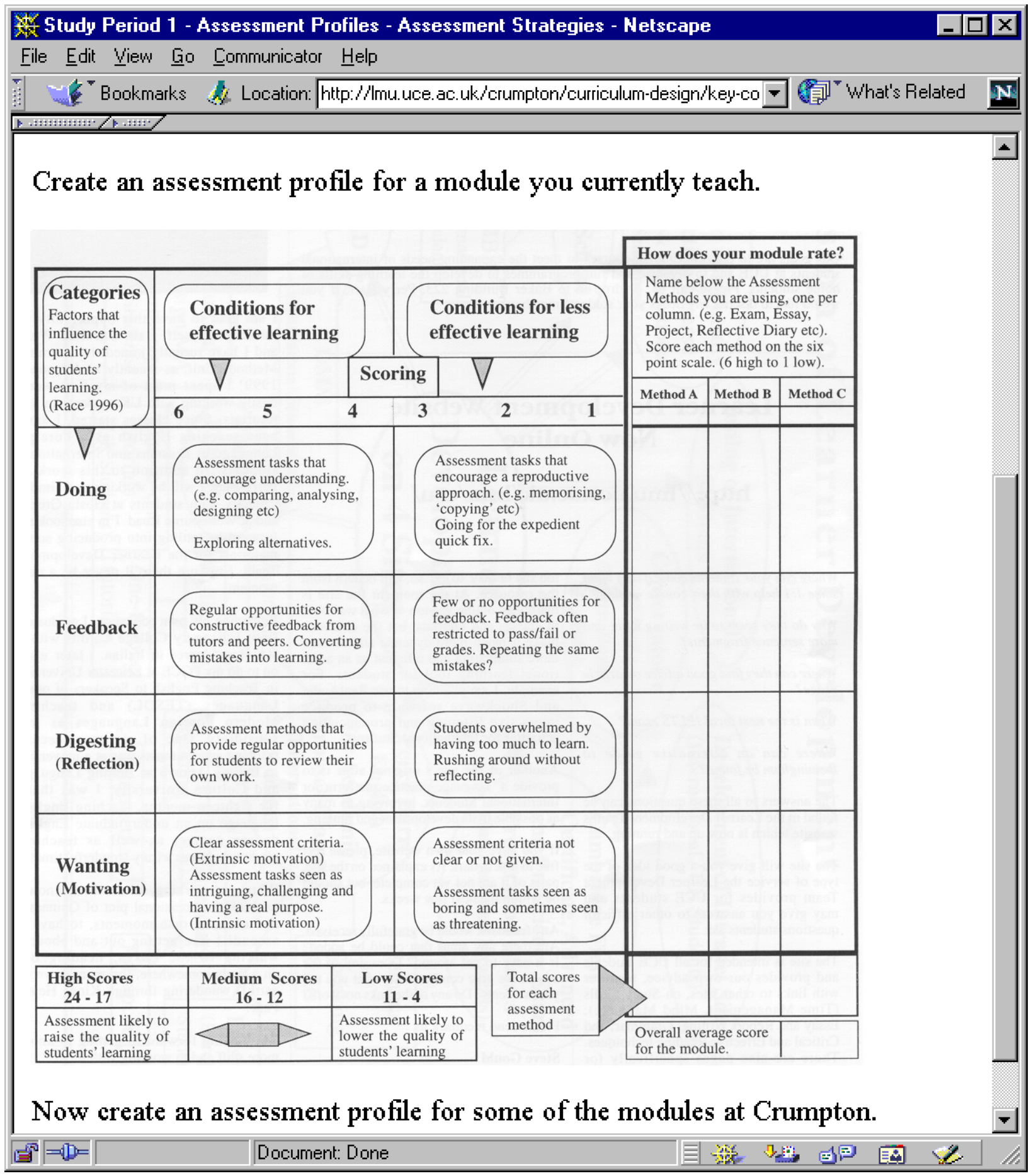

Figure 8. An Example of a Web-based Learning Activity. 


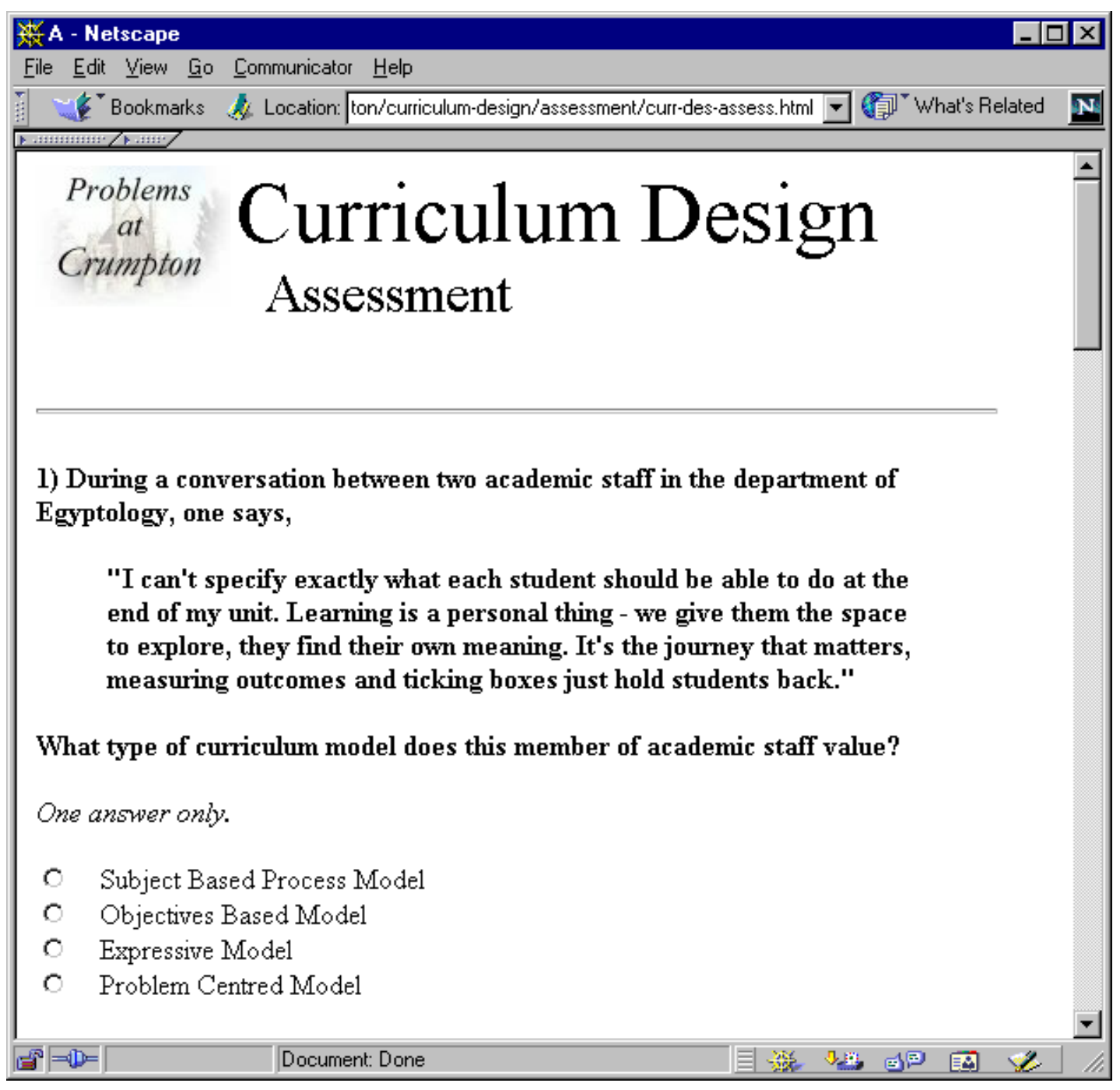

Figure 9. An Example of Online Objective Testing.

However, fundamental to the CSEL project is the belief that students will need to "break free" from the computer and perform some tasks in very applied situations, for example, the workplace, laboratory or studio. Therefore a central feature of the web pages is a problem-centred curriculum, that sets the learning context and promotes learning by doing [24].

\section{DEVELOPMENTS AND PROGRESS}

The theories that underpin this paper have been conveyed to academic staff within the University of Central England (UCE) by asking staff to take part in an online staff development exercise that represents phase 1 of the CSEL project. The participation of staff in this voluntary exercise has been described in [23]. The outcome of Phase 1 was to encourage approximately 40 staff to embed the use of learning technology in their own course modules in Phase 2 of the project. Staff who are teaching a range of subjects are now experimenting with applying technology to the CSEL model or parts of it, as they deem appropriate. A variety of technologies are being utilized, 
and individual projects may emphasise certain technologies more than others. A systematic evaluation of these individual projects is being performed by the Centre of Research into Quality at UCE using a variety of research methods that focus primarily on the quality of student learning. By comparing the outcomes of each of these projects it is hoped that the applicability of the CSEL model can be tested, and the implications of technology enhanced learning be understood more fully.

The "Problems at Crumpton" project, is at the time of writing, about to be used in the Postgraduate Certificate of Education, a course for academic staff within the university. Traditional classroom sessions will remain and the online component will represent a considerable portion of the staff's independent learning between formal classes. This project will be evaluated alongside the other faculty-based projects, but in addition the opportunity will be taken to research the impact of assessment, as contributions to the conference will be summatively assessed in accordance with clearly defined criteria. It is anticipated that analysis of server logs will give some indications as to how staff have approached learning. Will staff adopt a surface approach, doing just enough to pass, or will they study deeply, making extensive use of the Crumpton site?

The electronic learning contract is currently being developed, and once complete will be piloted with a small group of postgraduate students. The experience of using this contract will be researched alongside more general research into work-based learning.

The outcomes from all of these individual projects, and the comparative evaluations, will form the basis of further research publications.

\section{CONCLUSIONS}

This theoretical paper has considered the potential for using technology to re-design the curriculum, and has provided a model to help curriculum designers and technologists in their attempts to apply technology appropriately. The authors suggest that automating traditional approaches to higher education via the Web is unlikely to add significant value to the learning process beyond increasing access, but promote the view that the technology does offer the potential to reengineer the curriculum and enable more constructivist approaches. In particular, it is suggested that Asynchronous Learning Networks can play an important role in helping students to connect theory and practice, and increase the opportunity for effective experiential learning.

Applied research and development is currently being carried out in a variety of contexts to establish whether or not the authors' views can be substantiated. Results from a number of projects and independent comparative evaluations will be published to finalise the Computer Supported Experiential Learning project at the University of Central England in Birmingham, U.K.

\section{REFERENCES}

1. English, S., and Yazdani, M., Computer-Supported Cooperative Learning in a Virtual University, Journal of Computer Assisted Learning, 15, pp. 2-13, 1999.

2. Hammer, M., Reengineering Work: Don't Automate, Obliterate, Harvard Business Review, pp. 104112, July-August 1990.

3. Scheurman, G., From Behaviorist to Constuctivist Teaching, Social Education, 62(1) pp. 6-9, 1998.

4. Bligh, D., What's the Use of Lectures?, Penguin, 1972. 
5. Gibbs, G., Twenty Terrible Reasons for Lecturing, Standing Conference on Educational Development, 1982.

6. Harvey, L., and Green, D., Employer Satisfaction--Summary, Birmingham, Quality in Higher Education Unit, 1994.

7. Crook, C.K., Making Hypertext Lecture Notes More Interactive: Undergraduate Reactions, Journal of Computer Assisted Learning, 13, pp. 236-244, 1997.

8. Cohen, D., and Kasser, J., Creating the Voice Lecture-Presentation, Fifth International Conference on Asynchronous Learning Networks, University of Maryland University College, Maryland, U.S.A, 1999. http://www.aln.org/alnconf99/presentations/convertedfiles/16/

9. Daniel, J.S., Mega-Universities and Knowledge Media: Technology Strategies for Higher Education, Kogan Page, London, 1996.

10. Plater, W.M., Future Work: Faculty Time in the $21^{\text {st }}$ Century, Change, 27, pp. 23-33, 1995.

11. Ritzer, G., McUniversity in the Postmodern Consumer Society, Quality in Higher Education, 2 (3), pp. 185-99, 1996.

12. Asynchronous Learning Networks. http://www.aln.org

13. Bruner, J., Going Beyond the Information Given, New York, Norton, 1973.

14. Bruner, J., Actual Minds, Possible Worlds, Cambridge, MA, Harvard University Press, 1986.

15. Dubrovsky, V., Kiesler, S., and Sethner, B., The Equalisation Phenomenon: Status Effects in Computer-Mediated and Face-to-Face Decision Making Groups, Human Computer Interaction, 6, 119146, 1991.

16. Steeples, C., Unsworth, C., Bryson, M., Goodyear, P., Riding, P., Fowell, S., Levy, P., and Duffy, C., Technological Support for Teaching and Learning: Computer-Mediated Communications in Higher Education (CMC in HE), Computing and Education, Vol. 26, No. 1-3, pp. 71-80, 1996.

17. Harris, R., Computer-Conferencing Issues in Higher Education, Innovations in Education and Training International, 36,1 pp. 80-91, 1999.

18. Mason, R., Refining the Use of Computer Conferencing in Distance Education, in O. Boyd-Barrett and E. Scanlon (eds), Computers and Learning, Wokingham, Adison Wesley, 1991.

19. Gibbs, G., The Seminar, The New Academic, pp. 4-5, Summer 1992.

20. Kolb, D., Experiential Learning--Experience as the Source of Learning and Development, New Jersey, Prentice Hall, 1984.

21. Honey, P., and Mumford, A., The Manual of Learning Opportunities, Peter Honey, Maidenhead, 1989.

22. Elton, L. Strategies to Enhance Learner Motivation: a Conceptual Analysis, Studies in Higher Education, Vol. 21, No 1, pp. 57-67, 1996.

23. Staley, A., and Eastcott, D., Computer Supported Experiential Learning (Phase One--Staff Development), ALT-J, 7 1, pp. 39-45, 1999.

24. Gibbs, G., Learning by Doing: A Guide to Teaching and Learning Methods, Further Education Unit, 1988.

25. Goodyear, P., and Steeples, C., Creating Shareable Representations of Practice, ALT-J, 6 3, pp. 1623, 1998.

26. Collins, A., Cognitive Apprenticeship and Instructional Technology (Technical Report No. 6899), BBN Labs Inc, Cambridge, MA, 1988.

27. Stillman, G., Alison, J., Croker, F., and Tonkin, C., Situated Learning as a Model for the Design of an Interactive Multimedia Program on Medication Administration for Nurses, Innovations in Education and Training International, 35, 4, pp. 329-336, 1998.

28. Whittington, C.D., and Cambell, L.M., Task-Oriented Learning on the Web, Innovations in Education and Training International, 36, 1, pp. 26-33, 1999.

29. Problems at Crumpton. http://lmu.uce.ac.uk/crumpton

30. Jerrard, R., Staley, A., and MacKenzie, N., Learning Contracts in Masters Design Courses, Researching Work and Learning: A First International Conference, Trinity and All Saints College, Leeds, U.K, 1999.

31. Warren, K.J., and Rada, R., Sustaining Computer-Mediated Communication in University Courses, Journal of Computer Assisted Learning, 14, pp. 71-80, 1998.

32. Boud, D.J., and Feletti, G., Eds., The Challenge of Problem Based Learning, Kogan Page, London, 1991. 
33. Biggs, J.B., Student Approaches to Learning and Studying, Melbourne, Australian Council for Educational Research, 1987.

34. Biggs, J.B., Approaches to Learning: Nature and Measurement of, The International Encyclopedia of Education, Vol. 1 (2 $\left.{ }^{\text {nd }} E d\right)$, Oxford, Pergamon Press, 1994.

35. Buzan, T., Use Your Head, $3^{\text {rd }}$ Edition, BBC Books, London, 1989.

36. Riding, R., and Cheema, I., Cognitive Styles--an Overview and Integration, Educational Psychology, Vols. 11, 3 and 4, pp. 193-215, 1991.

37. Riding, R., and Sadler-Smith, E., Type of Instructional Material, Cognitive Style and Learning Performance, Educational Studies, 18 3, pp. 323-340, 1992.

\section{ABOUT THE AUTHORS}

Alan Staley is Head of Research in the Learning Methods Unit, and manager of the Computer Supported Experiential Learning Project (CSEL). His research is focused upon using technology appropriately to improve the quality of students' learning.

Niall MacKenzie is Research Fellow for the CSEL project and also works in the Learning Methods Unit. He developed the project's web site, maintaining this and administering the other online technologies on the LMU server. His research is also focused upon the thoughtful and appropriate use of technology in teaching and learning. 